\title{
Palliative Care and Socio-Cultural Interactions in French Guiana: A Case Report and Discussion
}

\author{
Gaëlle Saintomer ${ }^{1}$, Elisabeth Pion², Olivia Crépeau-Boespflug ${ }^{3}$, Stéphan Gonon ${ }^{4}$, Béatrice Virjoghé- \\ Cenciu $^{5}$, Olivier Laborde ${ }^{6}$, Jérome Fayette ${ }^{7}$, Jean-Pierre Droz ${ }^{8^{*}}$ \\ ${ }^{1}$ RN, Mobile Palliative Care Team, Centre Hospitalier Andrée-Rosemon, Cayenne (French Guiana) \\ ${ }^{2}$ Social Worker, Oncology Day Hospital, Centre Hospitalier Andrée-Rosemon, Cayenne (French Guiana) \\ ${ }^{3}$ MD, Head Mobile Palliative Care Team, Centre Hospitalier Andrée-Rosemon, Cayenne (French Guiana) \\ ${ }^{4} \mathrm{MD}$, Coordinator of HAD French Guiana - home hospitalization, Cayenne (French Guiana)
}

${ }^{5} \mathrm{MD}$, Attending physician, Oncology Day Hospital, Centre Hospitalier Andrée-Rosemon, Cayenne (French Guiana)

${ }^{6} \mathrm{MD}$, Attending physician, Gynecology-Obstetrics Department, Centre Hospitalier Andrée-Rosemon, Cayenne (French Guiana)

${ }^{7} \mathrm{MD}, \mathrm{PhD}$, Attending physician, Oncology Day Hospital, Centre Hospitalier Andrée-Rosemon, Cayenne (French Guiana) and Department of Medical Oncology, Centre Léon-Bérard, Lyon, France

${ }^{8} \mathrm{MD}, \mathrm{PhD}$, Attending physician, French Guiana Oncology Network Cayenne (French Guiana) and Emeritus Professor of Medical Oncology Claude-Bernard-Lyon1 University Lyon, France

Received: November 01, 2017; Accepted: November 15, 2017; Published: December 21, 2017

*Corresponding author: Jean-Pierre Droz, MD, PhD, Emeritus Professor of Medical Oncology, Claude-Bernard Lyon 1 University, Research Unit Cancer \& Environment, Centre Léon-Bérard, Lyon, France, Tel : 33643178 411; E-mail : jpdroz@orange.fr

\begin{abstract}
Context : Palliative care involves global management of the patient at the end of life. In the practice of oncology, important cultural aspects of this care are not always adequately taken in account.

Objective: To describe social, familial, economic and cultural aspects of end of life care through a case report of a patient with cancer of the cervix living in a multicultural setting.

Data Acquisition: Mrs. X, whose case is reported, was one of the 594 patients managed at the Cayenne Oncology Unit in French Guiana between January 2010 and December 2012. Mrs. X's trusted representative in confidential matters was her 21-year- old sister, who gave oral permission for anonymized data relating to the case to be published. The search for relevant references was guided by the nature of the data and discussion between authors.
\end{abstract}

Findings: Mrs. X's clinical presentation was typical for cancer of the cervix. Initial treatment was with curative intent led to incomplete resection. However, disease progression quickly made her case one of palliative management, and this raised many social, economic, family and cultural issues. These included illegal immigration, poverty, lack of structured family support, and aspects of indigenous cultural practice. The first three aspects were effectively managed by social workers. Cultural aspects, however, were not well understood. The objective was that the patient should die in her home surroundings and receive appropriate cultural death rites. This Native American patient was thought to belong to a cultural group whose death rites have disappeared. In fact, she belonged to a different group that had also lost its cultural identity.

Conclusions: Knowing patients' medical history is essential to planning effective palliative care. But it is also important to understand as fully as possible their social, familial and cultural circumstances. In relation to a patient's culture, we must not rely on general assumptions but should seek to understand the specific circumstances relevant to a particular individual.

Keywords: Cancer; Multicultural Populations; Death Rites; Palliative Management; Socioeconomic Status

\section{Introduction}

French Guiana is a French Overseas Department with the same health care system as European France, but the population and its culture are fundamentally different. The territory, located on the north-eastern coast of South America, has an area of 84,000 $\mathrm{km} 2,95 \%$ of which is equatorial forest. The official population is 229,000 , but there are approximately 40,000 illegal immigrants. The majority of inhabitants live close to the Atlantic coast which is the site of the three major cities: Cayenne (population 127,000), Saint-Laurent du Maroni $(33,700)$ and Kourou $(25,900)$. The 
remainder of the population lives in small village territories of 2,000 to 8,000 inhabitants, with sometimes only a few dozen living in the village itself. Figure 1 shows a map of the territory. The GDP per capita is 9,837 Euros (30\% of the 32,921 euro per capita GDP in European France).

The official rate of unemployment is high: $20 \%$ of the workingage population overall and 31\% among people aged less than thirty. Similar proportions may be unemployed but not counted in the statistics. Fifty-three percent of those aged under 15 do not have high-school diplomas. The political, administrative and health care structures are the same as in European France.

The Centre Hospitalier Andrée-Rosemon in Cayenne is a university hospital within the framework of the University of French West Indies - Guiana. The most developed and active services relate to obstetrics and pediatrics, tropical medicine, and to emergency medicine and intensive care.

Eighteen health care centers linked to the Cayenne hospital are spread around the territory.

The population of French Guiana is expanding, with an annual growth rate of $3.9 \%$ and a projected population for 2030 of 424,000 . The diverse population is made up of $40 \%$ Guyanese and French West Indies creoles, 10\% French Caucasian Europeans, Haitians (10\%), Brazilians (10\%), and Surinamese $(10 \%)$. There are small numbers of Chinese and Guyanese. There are also two distinct indigenous groups: Native Amerindians and Bushinengue, also called "maroons", comprise 8,000 and 45,000 people respectively. There are major cultural differences between the different groups.

This case report describes a patient, Mrs. X, with a typical cancer presentation but one accompanied by the many social, economic, familial and cultural issues that are typically encountered in French Guiana. Such problems may also occur in the management of cancer patients in low-income countries and in immigrant populations in high income countries.

\section{Patient and Methods}

Mrs. X was one of 594 patient scared for at the Cayenne Oncology Unit between January 2010 and December 2012 [1]. The series of 594 cases was the subject of a thesis for an MD degree (LB), a study reviewed and approved by the University of French Guiana and West Indies Medical School Institutional Review Board. Mrs. X appointed her 21-year-old sister, who lived in Cayenne, as her trusted representative in confidential matters. Mrs. X's sister gave oral consent to publication of anonymized data relating to the case. A retrospective study of the clinical files was conducted by those involved in her management. This included the gynecology department, the medical oncology day hospital, the supportive care board, and the Mobile Palliative Care Team (MPCT).

The search for relevant references on pubmed ${ }^{\mathrm{TM}}$ and Google ${ }^{\mathrm{TM}}$ was guided by the nature of the data and discussion between authors.

\section{Patient's Medical History}

Mrs. X was aged 38 when she presented in May 2010 with a complaint of genital bleeding for a couple of weeks. Gynecological exam discovered a tumor of the cervix and biopsy confirmed an infiltrating poorly differentiated carcinoma. The stage was T2bN1M0 clinically and on whole-body CT scan. Mrs. X had no significant comorbidities such as diabetes, hypertension or impaired renal function.

She was treated in a French West Indies hospital and received radio-chemotherapy: 45 Gy over 5 weeks, 9 Gy/week in 5 fractions of 1.8 Gy with Cisplatin $40 \mathrm{mg} / \mathrm{m} 2 /$ week. A 15 Gy brachy therapy boost was technically impossible due to stricture of the cervix, but a boost of 20 Gy was given by external beam radiotherapy. In February 2011, two months after this protocol had ended, CT scan revealed the persistence of a $20 \mathrm{~mm}$ cervical tumor and an extension to the right adnexa.

Salvage surgery was decided on and in March 2011 the patient underwent an enlarged colpo-hysterectomy (Piver II) and incomplete resection of a $50 \mathrm{~mm}$ residual right iliac lymph node. No further lymph node dissection was possible due to sclerosis. No peritoneal abnormality was seen. The pathological report showed a tumor invading the cervix and the uterine isthmus of $45 \mathrm{~mm}$ diameter; invasion of the whole isthmus endometrium; lymphatic and vascular embolisms; and extension to the right parameter. There was no invasion of the myometrium or of the vagina. Peritoneal cytology was normal. The residual lymph node was sclerotic and did not contain tumor cells. On microscopy, the tumor was poorly differentiated epidermoid infiltrating carcinoma.

One month later Mrs. X had recovered, but she complained of cystitis and diarrhea. As the exeresis was complete (R0), the patient was followed every 3 months with gynecological exam and CT scan. Follow-up gynecological exam demonstrated a local relapse and CT a relapse in the pelvis, with spread in the lombo aortic and mediastinal lymph nodes. Her creatinine clearance was $71 \mathrm{ml} / \mathrm{min}$, and her performance status (PS) 0 .

Mrs. X was hospitalized at the Cayenne Hospital from November 11th 2011 until January 24th 2012 and received palliative chemotherapy: two cycles of Cisplatin $50 \mathrm{mg} / \mathrm{m} 2$ day 1 and Topotecan $0.75 \mathrm{mg} / \mathrm{m} 2 /$ d, days $1,2,3$ (day 1 = day 21). Evaluation showed progressive disease; creatinine clearance was $44 \mathrm{ml} / \mathrm{min}$; PS was 2; and there was bilateral ureteral obstruction. A decision was made to switch to Paclitaxel $80 \mathrm{mg} / \mathrm{m} 2 / \mathrm{d}$ on days 1, 8, 15 and Carboplatin AUC 4, but the patient received only days 1 and 8 of the first cycle. An attempt to place JJ tubes was unsuccessful due to bladder involvement. Nephrostomy was not reasonable in this setting. Due to rapid disease progression, poor tolerance of chemotherapy and worsening performance status, it was decided that that patient should receive palliative management.

The gynecology team contacted the Mobile Palliative Care Team (MPCT) consisting of a board-certified palliative care physician, a trained registered nurse for palliative care and a 
psychologist. The social worker in charge of the patient was from the medical oncology outpatient clinic. The patient was visited by her sister. The medical team was concerned by the medico-social and psychological situation of the patient and family.

On November 28th 2011 the clinical exam revealed anorexia, no weight loss, and grade $5 / 10$ pain -- despite oral morphine which was localized in the pelvis and increased by urination and going to stool. The insufficient effect of morphine was partly due to poor implementation by the nursing team, and partly to Mrs. $X$ 's reluctance to receive this drug. Significant anemia was caused by hematuria. Mrs. X complained of urinary leakage, but refused urinary protection (a urethral tube was not tolerated). Oral food intake was limited, despite the absence of oral mucositis. She received oral nutritional supplements. There was constipation secondary to the morphine but also probably in relation to invasion of the pelvis. Mobility was limited to a perimeter of about four meters; Mrs. X attained a sitting position only very briefly, and her usual position was lying in bed. Thus the PS was 3. There were no cutaneous complications.

\section{Social and cultural context}

Mrs. X spoke French and Brazilian, but she was assumed to be a Palikur, one of the Native American groups living in the east part of the French Guiana and in the Amapa state in Brazil. She was completely informed of her disease at initial diagnosis, of all treatments following progression, and of the palliative objective of chemotherapy. She was also informed of and shared the decision to limit subsequent management to palliative care. She was aware of the fact that progressive renal insufficiency was lifethreatening, and she spontaneously raised the subject of dying in her village and her home (or "where she was living"). She did not mention belonging to a particular church.

The difficult family context weighed on the patient's mood. She was distressed by the emotional and cultural isolation which resulted from being hospitalized. Her aim was to find her son and her family, particularly her husband in St Georges-de-l'Oyapock, and her 10-year-old daughter, currently with a foster family in Cayenne. Her objective was to reunite the siblings. She was supported during hospitalization by her sister who maintained the connection with her family: her husband, her 10-year-old daughter and the foster family in Cayenne. Her husband and family supported her return home. The various health care providers committed themselves to fulfilling Mrs. X's request to return home to die.

Located on the eastern border of French Guiana, on the banks of the Oyapock River, Saint-Georges is $189 \mathrm{~km}$ from Cayenne [Figure 1]. It has a health care center with a medical doctor and a nurse and three observation beds for a maximum duration of 72 hours. Transfusions cannot be carried out.

The social worker assessed the patient's administrative status, her financial situation in relation to medical care and her social conditions. Mrs. X lived in a traditional Native Amerindian wooden house on stilts at the entrance of Saint-Georges in a community village [Figure 2]. The dwellings did not have electricity, water was available only from the well, and the toilets were shared and located at the bottom of the garden. The equipment of the house was rudimentary, consisting of a stove and hammocks. The rainy season makes travel difficult. The family had few resources and would not have been able to assume the cost of repatriating the body to Saint-Georges if Mrs. X were to die in Cayenne.

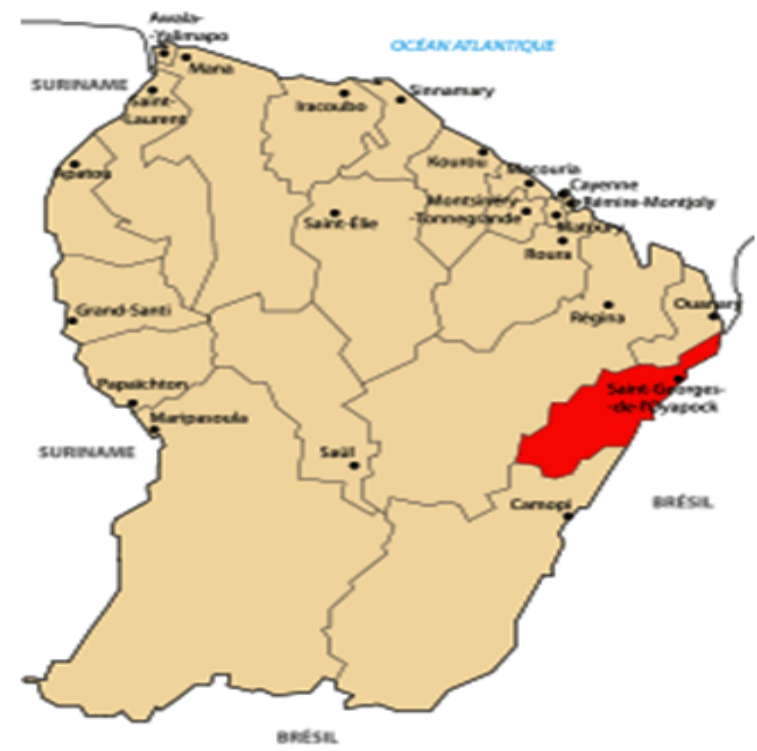

Figure 1:Map of French Guiana and the commune of Saint-Georges de l'Oyapock (French Guiana)

(From Wikimedia Commons, the free media repository- 2003)

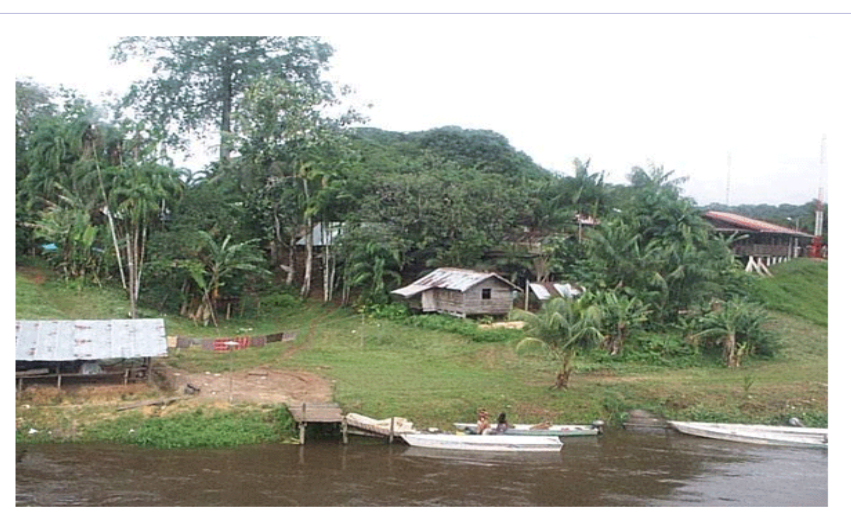

Figure 2:Traditional Native Amerindian wooden house on stilts at the entrance of Saint-Georges (Photograph by the first author)

\section{Results}

A telephone conference on January 9th 2012 between the Saint-Georges health care center doctor and nurse, the MPCT, and the social worker at the Cayenne Hospital explored the family's circumstances and the facilities available. Neither the health care center nor the medical equipment supplier in Cayenne had a pneumatic medical bed; but a bed could be lent by the SaintGeorges center. Material needed for palliative care could be delivered the week following Mrs. X's return home. 
The multidisciplinary team meeting of January 10th 2012 (Oncology Day Hospital, MPCT) established that the patient would benefit from a blood transfusion before departure with target hemoglobin of $12 \mathrm{~g} / \mathrm{dl}$. It was accepted that the transfusion could not be repeated regardless of the deteriorating general condition of the patient. Mrs. X was informed of the medical conditions of the return home, but she continued to make that her objective.

Discharge was scheduled for January 25th 2012. On January 24 th, the patient's condition was severely impaired, but the need for discharge was confirmed with the family and the health care center. A laissez-passer and a medical certificate were issued so that Mrs. X could return home even if she died on the journey.

The patient arrived home on the evening of January 24th 2012 and died during the following night. Mrs. X's body was kept for 48 hours free of charge by the village town hall so that her husband could make a coffin and arrange burial. Nevertheless the grave is now unmarked.

Subsequently, we investigated the socio-cultural situation of the patient in greater depth. Mrs. X was born in Aldeia Cupiri on the Cupiri River in the Amapa state of Brazil. She was a Karipuna, one of the Native American groups living in Amapa state but had immigrated to Saint-Georges de l'Oyapock 20 years earlier. She had a husband who was also a Karipuna. They lived from fishing and hunting but she stayed at home. When she became ill, their relationship became difficult with her husband prone to violence and alcoholism.

Mrs. X and her husband had four children. Two adult daughters never contacted their mother. A 7 year old son lived with his father in Saint-Georges, after several attempts to place him in care had failed. A 10-year-old girl had been placed in a foster family in Cayenne three years before. Several attempts to permit the young daughter to come in Mrs. X 21-year-old sister's home in Cayenne to see her mother were possible with the help of the foster family: this allowed informing and supporting this young girl. Thus Mrs. X's sole source of help was her own sister living in Cayenne who was her "person of confidence" and maintained the link with her husband and family in Saint-Georges.

Mrs. X had a Brazilian passport which allowed her to travel to the French West Indies to receive radiotherapy in 2010, but she was still an illegal immigrant. She was eligible only for Emergency Medical Help (AME) [2].

We had assumed that her origin was Palikur but in fact it was Karipuna. This was the reason why when arriving in SaintGeorges there were no specific Palikur death rituals. At the time, the medical team had thought it was important for the patient to die and be buried according to the Palikur death rites, as would be the case for a member of larger and more familiar Native American groups such as the Ka'lina.

\section{Discussion}

This patient, born in Brazil, suffered from cervical cancer. From 2003 to 2009, the overall cancer incidence rate among men and women in French Guiana was 30\% lower than the standardized rate in European France, the difference being statistically significant [3].

However, the age-standardized incidence of cervical cancer in French Guiana was four times higher than in European France and the mortality rate 5.5 times higher [4]. Despite a higher GDP per capita, the age-standardized incidence rate in French Guiana is close to those in the neighboring countries of Brazil and Surinam.

Because of the absence of screening for cervix cancer, women living in remote areas are diagnosed later and are more frequently already symptomatic that those in more easily accessible parts of the country. The stage at diagnosis was the major factor influencing Mrs. X's prognosis. More generally, access to care for migrants is challenging and poor access sustains health inequalities. In French Guiana, early detection and prevention programs are crucial for increasing cancer survival, notably for foreign-born patients. Late diagnosis, advanced stage at diagnosis, difficulties in accessing treatment facilities, and absence of prevention and screening are common problems in tropical countries which generally are of low and middle-low income [5-9]. Surprisingly this is also the case for a large proportion of the population in French Guiana [10].

The patient described suffered cumulatively from many of the problems which could occur: she was an illegal immigrant, had no health insurance coverage and no financial resources, and she was from a culture with a small number of members and practices different from those of the larger groups in the population.

In French Guiana, the last census in 2014 estimated the population at 252,338 inhabitants, of whom $40 \%$ were immigrants. Three-quarters of the immigrants were born in Haiti, Brazil and Surinam. Clandestine miners are estimated to amount to 8,000 people and illegal immigrants to $10-20,000$ [11]. This is a worldwide problem: in Africa, the number of internal migrants was estimated at 70 million people in 2009. An additional round 1.5 million had migrated to Europe [12].

This patient had lived in French Guiana for 20 years. Generally, most patients are covered by one or other of the various national health insurance systems. In French Guiana $60 \%$ of people are covered by the national health insurance, $28 \%$ by universal social insurance (CMU), and $12 \%$ by the emergency Medical Help (AME).

Illegal immigrants have no health insurance coverage, nevertheless in cases of severe medical emergency, social services can help the patient by applying for a residence permit for health care and Emergency Medical Help (AME) $[2,13]$. To obtain this permit, the requirements are: copy of proof of identity with photo (passport, identity card, birth certificate with photo), one proof of residence dating less than three months old, identity photographs, envelopes stamped at the current rate, proof of prolonged residence in France, proof that the medical file has been deposited with the Regional Health Agency (ARS): joint declaration on honor and all documents establishing the 
veracity and duration of the community of life. Meeting these administrative requirements is extremely time consuming and necessitates the co-operation of multiple players including the police, social security, and social services.

The Palikur live in the eastern part of French Guiana, having originated in north-eastern Brazil [14].The population is 1600 individuals. The Palikur language belongs to the Arawak group and $50 \%$ of the population still speaks it [15]. Their villages are located mainly next to the Oyapock River [16]. The Palikur have a patrilineal and exogamous clan structure and practice slash-andburn cultivation producing principally couak and manioc beer (kashiri) [17]. They also hunt and fish. Craftsmanship is a vivid cultural tradition.

In French Guiana they live close to Creole villages. During the 1960s, the North American Summer Institute of Linguistics (SIL) penetrated Palikur society in Brazil. They translated the Bible into Palikur and converted a large part of the population to Evangelical Christianity. Christian Palikur is told to reject traditional rituals such as feasting (dancing, kashiri drinking and bark smoking).

Until recently, the Palikur of the Oyapock maintained clan cemeteries. The bones were prepared by putrefaction in a first burial and then deposited in a second urn after a period of conservation by the family of the deceased [18]. When Palikur die in foreign lands, there is an obligation to repatriate at least a part of the deceased's body to the native territory. This practice testifies to the absence of rupture with the dead [16].Although such funeral practices have declined, holding the funeral rites within the dead person's territory still has great importance This justified the need to make arrangements so that Mrs. X could die in her village. However, it turned out that this patient did not in fact belong to the Palikur cultural group.

Her birth place -- Aldeia Cupiri on the Cupiri River, near Manga - should have attracted our attention, since this area is historically the geographical origin of Karipuna. The history of the Karipuna is linked to the delimitation of the Franco-Brazilian border on the Oyapock River in 1900 and the history of what was called the "Contested Territory", now, the Brazilian state of Amapa. This territory, far from the economic centers of Brazil and poorly accessible from Belem, has long represented a refuge for Native Americans displaced by Portuguese pressure, for the maroons from Brazil and French Guiana, and later for the poor populations of the lower Amazon [19]. This territory has always had a special relationship with French Guiana. The Karipuna of today were formed by the integration and cohabitation of these populations from Amazonia, Pará or Guiana with each other and with the indigenous peoples and has become - in a little more than a century - a distinct culture [16]. Those who were still known at the beginning of the 20th century as "Brazilians of the Cupiri" (the name of the river where they were settled), only 150 people - became "Indians" for the Brazilian administration in the 1930s. The Brazilian policy was the assimilation with Portuguese teaching, nationalism and acculturation.

The Karipuna population, approximately 2,400 people in
2010, is now established in three main villages on the Cupiri River- Manga, Santa Isabel, Espirito Santo- and in some other small villages on the river (such as Aldeia Cupiri). The natives of the former "Contested Territory" tried to move to French Guiana where they would benefit from the privileges of being on French territory. However, although the population (especially given its Native American antecedents) was essentially "cross border", the administrative rules applied to limit mobility now give them the status of "migrants"[19].

\section{Conclusion}

The initial management of this patient with cervix cancer was based on western standards and was according to evidencebased-medicine. Mrs. X was treated within the French Health care system. However the disease progressed and the patient entered a phase of purely palliative treatment, which corresponded to current guidelines [20]. Difficulties were encountered due to the patient's status as an illegal immigrant, her poverty, absence of supportive family structure, and non-European culture. The three first aspects were dealt with by professional social workers and, although this was time consuming, it could deal with in a hospital. The cultural aspects, in contrast, required expert understanding of the cultures concerned and in-depth knowledge of the patient.

This patient was assumed to be a Palikur. As this population is small, the health professionals thought that their death rites were similar to those of the larger groups of Native Americans in French Guiana, such as the Ka'lina or Wayana. In fact they had made a double mistake. The first was in being unaware that nowadays the Palikur no longer practice ancestral rites. The second was in not realizing that the patient was not a Palikur but actually a Karipuna. None of the health professionals were aware of this population: only a retrospective bibliographic research allowed full understanding of Mrs. X's true situation.

Issues similar to those addressed in this case report may arise with cancer patients in low income countries and with immigrant patients in western countries. It is important to fully understand the medical history but also the social, familial and cultural characteristics of patients. If the cultural origin of patients is to be considered, we must not confine ourselves to general assumptions but should attempt to understand the precise circumstances of the individual.

\section{Acknowledgments}

Editorial support was provided by Rob Stepney (medical writer, Charlbury, UK)

The authors would like to thank Gérard Collomb, Michel Launey, Lux Vidal and Alexis Tiouka for their inputs to allow writing of this manuscript.

\section{Conflict of Interest}

None to Disclose

\section{Ethical Approval}

The entire 594 patient study was the subject of a thesis for an MD degree (LB), and it was reviewed and approved by the 
University of French Guiana and West Indies Medical School Institutional Review Board[1]. Her sister living in Cayenne who was her "person of confidence" gave oral consent to publication of her sister's story if anonymized.

\section{References}

1. Bianco L. Practice of equatorial oncology; Retrospective study over 4 years (2010-2013). IMG Thesis. 2014.

2. Universal health coverage office. Benefit of the State Medical Aid (AME) for undocumented immigrants. 2017.

3. Roue T. Epidemiology of cancers in French Guiana: Analysis of data from the Cancer Registry of French Guiana (in French). 2014.

4. Roue T, Nacher M, Fior A, Plenet J, Belliardo S, Gandolfo N, et al. Cervical cancer incidence in French Guiana: South American. Int J Gynecol Cancer. 2012; 22(5):850-853; Doi: 10.1097/IGC.0b013e318251722c

5. Amat-Roze JM. The health needs of people in tropical countries, growth of malignant diseases, and co-existence of extremes. In: Droz JP, Carme B, Couppié P, Thiéblemont C. Tropical Hemato-Oncology. Heidelberg, New York, Dordrecht, London: Springer; 2015:9-16.

6. Boyle P, Anderson BO, Andersson LC, Ariyaratne Y, Auleley GR, Barbacid $\mathrm{M}$ et al. Need for global action for cancer control. Ann Oncol. 2008; 19(9):1519-1521; Doi: 10.1093/annonc/mdn426

7. Denny LA, Sankaranarayanan R, De VH, Kim JJ, Adefuye PO, Alemany L et al. Recommendations for cervical cancer prevention in subsaharan Africa. Vaccine. 2013; 31 Suppl 5:F73-F74; Doi: 10.1016/j. vaccine.2012.11.077

8. Grundy E, Sloggett A. Health inequalities in the older population: the role of personal capital, social resources and socio-economic circumstances. Soc Sci Med. 2003; 56(5):935-947.

9. Lopez-Gomez M, Malmierca E, de GM, Casado E. Cancer in developing countries: the next most preventable pandemic. The global problem of cancer. Crit Rev Oncol Hematol. 2013; 88(1):117-122; Doi: 10.1016/j. critrevonc.2013.03.011

10. Valmy L, Gontier B, Parriault MC, Melle AV, Pavlovsky T, Basurko C, et al. Prevalence and predictive factors for renouncing medical care in poor populations of Cayenne, French Guiana. BMC Health Serv Res. 2016; 16:34; Doi: 10.1186/s12913-016-1284-y

11. French Senate. Clandestine immigration: an unacceptable reality, a firm, fair and human response (report in French). 2017.

12. Daum C, Dougnon I. Internal migration to the African continent (in French). Hommes et migrations 2009; (1272):6-11.

13. French Guiana prefecture. Application for a residence permit for health care. 2017.

14. Hurault J-M. Français et indiens en Guyane - 1604-1972 (in French). Cayenne: Guyane Press Difusion; 1989.

15. Launey M. Awna parikwani. Langue Palikur. Paris: IRD eds. 2003.

16. Grenand F, Grenand P. The coast of Amapa, from the mouth of the Amazon to the Oyapock Bay, through the Palikur oral tradition. (in French). Bol Mus Par Emilio Goeldi ser Anthropologia. 1987;3(1):177.

17. Anonymus. Expedito Arnaud. Supl Acta Amazonica. 1981;11(1):137148.

18. Chaumeil J-P. The bones, the flutes, the dead. Memorial and funerary treatment in Amazonia (in French). J Soc Americanists. 1997;83:83110 .

19. Collomb G. "Indians" or "Brazilians"? Karipuna Mobilities towards Cayenne (French Guiana). Rev Eur Migrations Intern. 2013;29(1):113131.

20. Ferrell BR, Temel JS, Temin S, Alesi ER, Balboni TA, Basch EM, et al. Integration of Palliative Care Into Standard Oncology Care: American Society of Clinical Oncology Clinical Practice Guideline Update. J Clin Oncol. 2017; 35(1):96-112; Doi :10.1200/JC0.2016.70.1474 